\title{
Comparative long-term results of mitral valve repair in adults with chronic rheumatic disease and degenerative disease: Is repair for "burnt-out" rheumatic disease still inferior to repair for degenerative disease in the current era?
}

\author{
Jeswant Dillon, MD, FRCS, ${ }^{a}$ Mohd Azhari Yakub, MBBS, FRCS, ${ }^{a}$ Pau Kiew Kong, MBBS, FRCS, ${ }^{a}$ \\ Mohd Faizal Ramli, BSc, MSc, ${ }^{b}$ Norfazlina Jaffar, BSc, ${ }^{b}$ and Intan Fariza Gaffar, BSc ${ }^{b}$
}

\begin{abstract}
Objective: Mitral valve repair is perceived to be of limited durability for advanced rheumatic disease in adults. We aim to examine the long-term outcomes of repair for rheumatic disease, identify predictors of durability, and compare with repair for degenerative disease.
\end{abstract}

\begin{abstract}
Methods: Rheumatic and degenerative mitral valve repairs in patients aged 40 years or more were prospectively analyzed. The primary outcomes investigated were mortality, freedom from reoperation, and valve failure. Logistic regression analysis was performed to define predictors of poor outcome.

Results: Between 1997 and 2011, 253 rheumatic and 148 degenerative mitral valves were repaired. The age of patients in both groups was similar, with a mean of $54.1 \pm 8.4$ years versus $55.6 \pm 7.3$ years $(P=.49)$. Freedom from reoperation for rheumatic valves at 5 and 10 years was $98.4 \%$, comparable to $95.3 \%(P=.12)$ for degenerative valves. Freedom from valve failure at 5 and 10 years was $91.4 \%$ and $81.5 \%$ for rheumatic repairs and $82.5 \%$ and $75.4 \%$ for degenerative repairs, respectively $(P=.15)$. The presence of residual mitral regurgitation greater than $2+$ before discharge was the only significant independent predictor of reoperation, whereas residual mitral regurgitation greater than $2+$ and leaflet procedures were significant risk factors for valve failure.
\end{abstract}

Conclusions: The durability of rheumatic mitral valve repair in the current era has improved and is comparable to the outstanding durability of repairs for degenerative disease, even in the adult rheumatic population. Modifications of standard repair techniques, adherence to the importance of good leaflet coaptation, and strict quality control with stringent use of intraoperative transesophageal echocardiography have all contributed to the improved long-term results. (J Thorac Cardiovasc Surg 2015;149:771-9)

See related commentary on pages $779-80$.

Mitral valve (MV) repair is preferred over replacement for its numerous benefits, including preservation of ventricular function, lower operative mortality, superior long-term survival, and avoidance of anticoagulation. ${ }^{1-3} \mathrm{MV}$ repair has excellent durability in patients with mitral regurgitation (MR) caused by degenerative disease ${ }^{4,5}$ and

\footnotetext{
From the Department of Cardiothoracic Surgery ${ }^{\mathrm{a}}$ and Clinical Research Department, ${ }^{\mathrm{b}}$ National Heart Institute, Kuala Lumpur, Malaysia.

This research is funded by the National Heart Institute (Institut Jantung Negara), Kuala Lumpur, Malaysia.

Disclosures: Authors have nothing to disclose with regard to commercial support.

Read at the 94th Annual Meeting of The American Association for Thoracic

Surgery, Toronto, Ontario, Canada, April 26-30, 2014.

Received for publication April 9, 2014; revisions received Aug 15, 2014; accepted for publication Aug 19, 2014; available ahead of print Oct 11, 2014.

Address for reprints: Jeswant Dillon, MD, FRCS, Department of Cardiothoracic Surgery, National Heart Institute, 145 Jalan Tun Razak, 50400 Kuala Lumpur, Malaysia (E-mail: jeswant@ijn.com.my).

$0022-5223 / \$ 36.00$

Copyright (C) 2015 by The American Association for Thoracic Surgery

http://dx.doi.org/10.1016/j.jtcvs.2014.08.066
}

is the established method of choice in the correction of MR whenever feasible.

In contrast, valve reconstruction for rheumatic MR remains controversial because it suffers from inferior feasibility of repair ${ }^{6}$ and the repaired rheumatic valve is perceived to be less stable with inferior durability compared with degenerative MV repair. ${ }^{7}$ Disease progression in such patients may lead to early valve failure and reoperation, thus affecting the durability of repair. ${ }^{8,9}$ Conversely, the results in some recent rheumatic repair series in the contemporary literature have been promising. ${ }^{10-14}$ Nevertheless, repair for rheumatic disease in the extremes of ages poses unique challenges. In children and adolescents, ongoing rheumatic inflammatory activity may predispose to reactivation with failure of repair. ${ }^{13,15}$ At the other end of the spectrum, chronic rheumatic disease in adults and the elderly with "burntout" disease is often accompanied with extensive tissue scarring, fibrosis, retraction, calcification, and stenosis, resulting in technical difficulties in repair and potentially compromising durability. ${ }^{16,17}$ In addition, the scarcity of data on long-term outcome in rheumatic MV repair, especially in adults, does not assist in resolving this issue. 


$$
\begin{aligned}
& \text { Abbreviations and Acronyms } \\
& \text { AF } \quad=\text { atrial fibrillation } \\
& \text { CI }=\text { confidence interval } \\
& \text { HR } \quad \text { hazard ratio } \\
& \text { MR }=\text { mitral regurgitation } \\
& \text { MS } \quad \text { mitral stenosis } \\
& \text { MV } \quad=\text { mitral valve } \\
& \text { NYHA } \\
& \text { TEE } \quad \text { New York Heart Association } \\
&
\end{aligned}
$$

We present a 15-year single-center experience of rheumatic MV repair in adults, aiming to determine its long-term outcomes, to identify predictors of durability, and to compare with the outcomes of repair for degenerative MV disease. The data were collected prospectively from our valve repair registry.

\section{MATERIALS AND METHODS \\ Patients}

From January 1997 to December 2011, 253 consecutive patients aged 40 years or more underwent MV repair for rheumatic disease (group R) at the National Heart Institute, Kuala Lumpur, Malaysia. Another 370 patients of similar age underwent MV replacement for rheumatic disease. The feasibility of MV repair in patients aged 40 years or more with rheumatic disease was $40.6 \%$. The feasibility of MV repair in patients with rheumatic disease differed according to the age of patients: $48.7 \%$ for patients aged 55 years or less and $34.5 \%$ for those aged more than 55 years. During the study period, 148 patients aged 40 years or more underwent MV repairs for degenerative disease, and they formed the control population (group D). Patients who underwent concomitant cardiac surgery for aorta, cardiac tumor, or pericardial diseases were excluded. However, patients who underwent concomitant surgery for aortic and tricuspid valve lesions and coronary artery bypass were not excluded. The age of patients in groups $\mathrm{R}$ and $\mathrm{D}$ was similar: mean, $54.1 \pm 8.4$ years versus $55.6 \pm 7.3$ years; median, 54 years versus 55 years; range, 40 to 75 years versus 40 to 72 years $(P=.498)$. Some $73.6 \%$ of patients in group D were male, and $60.5 \%$ of patients in group $\mathrm{R}$ were male $(P=.007)$. All but 1 patient $(0.7 \%)$ in group $\mathrm{D}$ had pure MR, whereas 42 patients ( $16.6 \%)$ in group $R$ had concomitant mitral stenosis (MS) and MR $(P=.001)$. A further 8 patients $(3.2 \%)$ in group $\mathrm{R}$ had isolated MS. Atrial fibrillation (AF) was present in 90 patients $(35.6 \%)$ in group $\mathrm{R}$ and 37 patients $(25 \%)$ in group $\mathrm{D}(P=.06)$. Shortness of breath on exertion was the predominant symptom, and 210 patients $(83.0 \%)$ in group R and 124 patients (83.8\%) in group D were in New York Heart Association (NYHA) functional class II or more. The demographic data and preoperative status of the patients are summarized in Table 1. This study received approval from the ethical committee of the institute.

\section{Preoperative Assessment}

Two-dimensional echocardiography and Doppler color flow imaging were performed in all patients using a Hewlett-Packard (Palo Alto, Calif) Sonos 2500 or Philips (Amsterdam, The Netherlands) IE 33 equipped with a 2.5- to 3.5-MHz transducer. Preoperative echocardiography was performed in all patients within 3 months before surgery. The morphology of the valve was documented to further substantiate the diagnosis of rheumatic MV disease. With the simplified proximal isovelocity surface area method, the degree of MR was graded as trivial or mild (1+MR), moderate $(2+\mathrm{MR})$, moderate to severe $(3+\mathrm{MR})$, and severe $(4+\mathrm{MR})$ on the basis of regurgitant volume and effective regurgitant orifice area. MV area was estimated using the pressure half-time method, and MS was graded on the basis of this and mean pressure gradient. In addition, all patients received intraoperative transesophageal echocardiography (TEE) to analyze the valve before and after valve repair. Coronary angiography was performed in all patients because they were aged 40 years or more.

\section{Surgical Procedures}

The standard surgical approach was median sternotomy and conventional ascending aorta and bicaval cannulation. Moderate hypothermic $\left(28^{\circ} \mathrm{C}\right.$ $32^{\circ} \mathrm{C}$ ) cardiopulmonary bypass was used, and myocardial protection was achieved with cold blood cardioplegia. The MV was approached through a left atrial incision parallel to the interatrial groove. MV repair techniques were based on Carpentier's reconstruction ${ }^{10}$ principles, although there were some modifications tailored to the individual patient. The prolapse or flail posterior leaflet was corrected mainly by leaflet resection or plication and supplanted in the later years with the introduction of polytetrafluoroethylene neochords. Chordal elongation or rupture of the anterior leaflet was primarily corrected by polytetrafluoroethylene chordal replacement, chordal shortening, or chordal transfer. In $16.6 \%$ of patients with combined MS and incompetence, commissurotomy was performed to increase the orifice area. Papillary muscle splitting, excision of thickened and shortened secondary chordae (and sometimes even primary chords), and thinning of leaflets were performed to improve mobility and pliability of the valve leaflets. In $18 \%$ of patients with rheumatic disease in whom leaflet mobilization was not enough to compensate for tissue retraction, leaflet extension with glutaraldehyde-treated autologous pericardial patch was performed. Leaflet extension increases the surface area of the leaflet and improves coaptation. This allows insertion of a larger annuloplasty ring, thereby reducing the risk of stenosis, which is especially important in those with rheumatic disease. In a recent publication, ${ }^{17}$ we described in detail the use of autologous pericardium for leaflet extension in patients with rheumatic disease. The majority of repairs, $97.2 \%$ in group $\mathrm{R}$ and $99.3 \%$ in group $\mathrm{D}$, were completed by placement of an annuloplasty ring. The most common types of rings used in both groups were the complete rigid or semi-rigid rings ( $80.1 \%$ in group $\mathrm{R}$ and $70.1 \%$ in group D). Details of the MV repair techniques performed in both groups are summarized in Table 2. At the completion of the repair, MV competency was assessed by injecting cold saline with a bulb syringe into the left ventricle through the MV. Further definitive assessment was performed by intraoperative TEE analysis after termination of cardiopulmonary bypass.

A total of 30 patients $(11.9 \%)$ in group $\mathrm{R}$ and 18 patients (12.2\%) in group D underwent concomitant surgery for AF. The modified Cox-Maze III procedure was performed using the "cut-and-sew" technique in 3 patients and radiofrequency ablation in 45 patients. We were selective in performing the Maze procedure in patients who had a high likelihood of success, mostly limiting the procedure to patients who had $\mathrm{AF}$ for less than 2 years and a left atrial size less than $6 \mathrm{~cm}$. In addition, 177 patients in group $R$ and 75 patients in group $\mathrm{D}$ underwent various other associated procedures. The most common concomitant procedures in both groups were tricuspid valve repair and coronary artery bypass grafting, performed in $28.9 \%$ and $28.9 \%$ of patients in group $\mathrm{R}$, respectively, and $26.4 \%$ and $20.9 \%$ of patients in group $\mathrm{D}$, respectively.

\section{Postoperative Management}

Patients who underwent prosthetic ring annuloplasty implantation were routinely administered warfarin for anticoagulation for 6 weeks postoperatively, with a target international normalized ratio of 2.0 to 3.0 , and continued indefinitely for those who had AF. Patients with rheumatic disease (aged $\geq 40$ years) were given oral penicillin as a secondary prophylaxis against rheumatic fever for 10 years, as was previously recommended although more recent guidelines advise lifelong use. ${ }^{18}$

\section{Follow-up}

All survivors were evaluated with echocardiography before discharge, at 3 months, at 6 months, and annually after surgery. Data on follow-up were obtained up to October 2013 and collected during the visits to the 
TABLE 1. Preoperative characteristics of patients in the rheumatic and degenerative groups

\begin{tabular}{lccc}
\hline Characteristics & $\begin{array}{c}\text { Rheumatic } \\
(\mathbf{n}=\mathbf{2 5 3})\end{array}$ & $\begin{array}{c}\text { Degenerative } \\
(\mathbf{n = 1 4 8})\end{array}$ & $\boldsymbol{P}$ value \\
\hline Sex & & & \\
$\quad$ Male & $153(60.5 \%)$ & $109(73.6 \%)$ & .007 \\
$\quad$ Female & $100(39.5 \%)$ & $39(26.4 \%)$ & \\
Age (y) & & & \\
$\quad$ Mean & $54.1 \pm 8.4$ & $55.6 \pm 7.3$ & .498 \\
$\quad$ Median & 54 & 55 & \\
Pathology & & $147(99.3 \%)$ & .001 \\
$\quad$ MR & $203(80.2 \%)$ & 0 & \\
MS & $8(3.2 \%)$ & $1(0.7 \%)$ & \\
MR/MS & $42(16.6 \%)$ & $117(79.1 \%)$ & .107 \\
NYHA class & & $31(20.9 \%)$ & \\
I and II & $173(68.4 \%)$ & & .028 \\
III and IV & $80(31.6 \%)$ & $111(75.0 \%)$ & \\
Rhythm & & $37(25.0 \%)$ & \\
$\quad$ SR & $163(64.4 \%)$ & & \\
AF & $90(35.6 \%)$ & & \\
\hline
\end{tabular}

$A F$, Atrial fibrillation; $M R$, mitral regurgitation; $M S$, mitral stenosis; $N Y H A$, New York Heart Association; $S R$, sinus rhythm.

outpatient clinic or by telephone interviews. The overall completeness of follow-up was $95.3 \%$ (98.0\% in group R and $90.5 \%$ in group D). The mean follow-up was 47.8 and 48.9 months in groups $\mathrm{R}$ and $\mathrm{D}$, respectively $(P=.335)$, and the maximum was 15.7 and 15.8 years in groups $\mathrm{R}$ and $\mathrm{D}$, respectively. Operative mortality was defined as death within 30 days of surgery or in-hospital death. Deaths were classified as cardiac or noncardiac on the basis of medical records. Valve-related complications, such as thromboembolic events, infective endocarditis, bleeding secondary to anticoagulation, or need for reoperation, were recorded during the follow-up. Valve failure was defined as recurrent significant regurgitation of more than 1+ MR (mild MR) or MV reoperation. Reoperation was performed for the same indications as for the initial operation.

\section{Statistical Analysis}

Data are presented as frequencies or means with standard deviations. Univariate analysis of categoric data was carried out with chi-square or

TABLE 2. Details of mitral valve repair techniques in rheumatic and degenerative groups

\begin{tabular}{lccr}
\hline Repair technique, $\mathbf{n}(\%)$ & Rheumatic & Degenerative & $\boldsymbol{P}$ value \\
\hline Ring annuloplasty & $246(97.2)$ & $147(99.3)$ & .148 \\
$\quad$ No ring & $7(2.8)$ & $1(0.7)$ & \\
Rigid/semi-rigid, complete & $197(80.1)$ & $103(70.1)$ & .085 \\
Flexible, partial & $49(19.9)$ & $44(29.9)$ & \\
Leaflet resection & $56(22.1)$ & $85(57.4)$ & $<.001$ \\
Leaflet plication & $12(4.7)$ & $12(8.1)$ & .170 \\
Leaflet shaving, thinning & $50(19.8)$ & $8(5.4)$ & $<.001$ \\
Leaflet extension, patch & $46(18.2)$ & $1(0.7)$ & $<.001$ \\
Chordal replacement (PTFE) & $51(20.2)$ & $51(34.5)$ & .002 \\
Chordal shortening & $19(7.5)$ & $12(8.1)$ & .829 \\
Chordal transfer & $17(6.7)$ & $13(8.8)$ & .448 \\
Chordal resection & $24(9.5)$ & $3(2.0)$ & .004 \\
Commissurotomy & $35(13.8)$ & $1(0.7)$ & $<.001$ \\
Commissuroplasty & $12(4.7)$ & $16(10.8)$ & .021 \\
Papillary muscle splitting & $20(7.9)$ & 0 & $<.001$ \\
\hline
\end{tabular}

PTFE, Polytetrafluoroethylene.
Fisher exact tests. Univariate analysis of continuous variables was carried out with the Student $t$ test. Logistic regression was used to determine the risk factors for early death. Cox regression analysis was used to determine the risk factors for reoperation and valve failure. Variables with a $P$ value of .1 or less in univariate analysis were subjected to the multivariate analysis. Analyses of survival and freedom from reoperation and valve failure were performed with the Kaplan-Meier. SPSS version 20.0 (SPSS Inc, Chicago, Ill) was used for statistical analysis.

\section{RESULTS \\ General Outcomes}

All patients survived the operation. The mean crossclamp time was $84 \pm 40$ minutes and the mean cardiopulmonary bypass time was $117 \pm 59$ minutes for group R, and this did not differ from the crossclamp time of $89 \pm 33$ minutes $(P=.111)$ and bypass time of $120 \pm 41$ minutes $(P=.509)$ for group D. Patients in groups R and D were treated in the intensive care unit for a median period of 1.5 days and 1 day, respectively $(P=.123)$, and the median hospital stay was 8 days in both groups $(P=.238)$.

\section{Early Outcome}

The overall 30-day hospital mortality (inclusive of patients who underwent concomitant cardiac procedures) was $4.3 \%$ (11 patients) in group $\mathrm{R}$ and $2.0 \%$ (3 patients) in group $\mathrm{D}(P=.222)$.

However, the early mortality rates for isolated MV repair was $1 \%$ and $0 \%$ for groups $\mathrm{R}$ and $\mathrm{D}$, respectively. Persistent low cardiac-output syndrome was the most common cause of death, responsible for 6 deaths. The other causes of early death included septicemia, malignant ventricular arrhythmias, acute renal failure, pneumonia, severe pulmonary hypertension, and multiorgan failure. Univariate analysis identified long cardiopulmonary time (odds ratio, 1.016; 95\% confidence interval [CI], $1.007-1.025 ; P<.001)$ and crossclamp time (odds ratio, $1.019 ; 95 \%$ CI, $1.008-1.030 ; P<.001)$ as the only significant predictors of early death. The other variables of age, sex, NYHA functional class, cause (rheumatic or degenerative), and surgery status (elective or emergency) were not predictive of early death.

\section{Late Outcome and Overall Survival}

There were $21(8.3 \%)$ late deaths within group $\mathrm{R}$ and $9(6.7 \%)$ late deaths in group $\mathrm{D}(P=.415)$. The overall 5- and 10 -year survivals were $90.9 \% \pm 2.1 \%$ and $83.3 \%$ $\pm 4.3 \%$, respectively, for group $\mathrm{R}$ and $88.6 \% \pm 3.8 \%$ and $88.6 \% \pm 3.8 \%$, respectively, for group $\mathrm{D}(P=.55)$ (Figure 1). The majority of the patients receiving follow-up were in NYHA class I ( $94.4 \%$ in group R and $96.9 \%$ in group D) and class II $(5.2 \%$ in group $\mathrm{R}$ and $2.3 \%$ in group $\mathrm{D})$; only 1 patient each in group $\mathrm{R}(0.4 \%)$ and group D $(0.8 \%)$ was in NYHA class III, and none were in NYHA class IV. Most of the survivors in our series had no residual MR $(28.7 \%$ in group $\mathrm{R}$ and $32.1 \%$ in group 


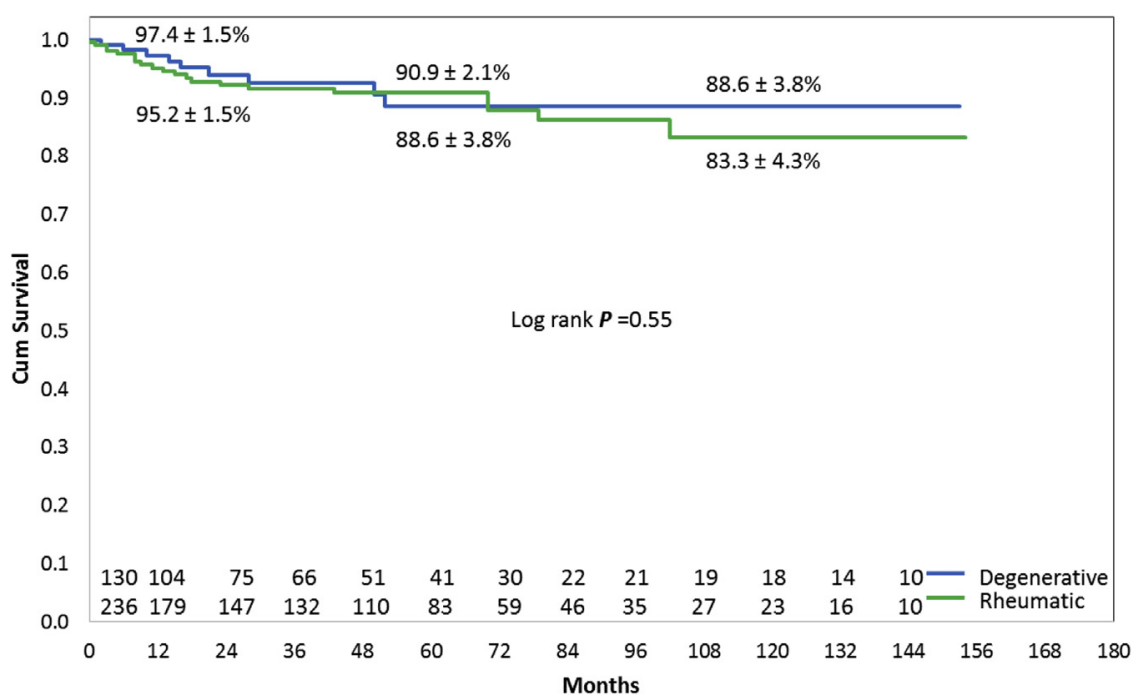

FIGURE 1. Actuarial survival for populations with rheumatic and degenerative disease. Survivals at 5 and 10 years were $90.9 \%$ and $83.3 \%$ in group R, respectively, and $88.6 \%$ and $88.6 \%$ in group $\mathrm{D}$, respectively $(P=.55)$.

D) or $1+$ MR (trivial or mild MR) $(60.8 \%$ in group $R$ and $52.3 \%$ in group $\mathrm{D})$ recorded at their last follow-up visit. Many of those who had residual $2+$ MR $(7.2 \%$ in group $\mathrm{R}$ and $11.9 \%$ in group $\mathrm{D})$ were asymptomatic. Most patients remained in or converted to sinus rhythm except for $20.6 \%$ of group R and $16.8 \%$ of group $\mathrm{D}$ who had AF ( $P=.61$ between the groups). None of the patients experienced thromboembolism, bleeding events related to anticoagulation, or endocarditis.

\section{Reoperation and Valve Failure}

Actuarial freedom from reoperation for patients with rheumatic disease at 5 and 10 years was $98.4 \% \pm 0.9 \%$, comparable to freedom from reoperation for patients with degenerative disease of $95.3 \% \pm 2.7 \%$ at 5 and 10 years $(P=.12)$ (Figure 2). Three patients in group $\mathrm{R}$ and 5 patients in group $\mathrm{D}$ underwent MV reoperation. The mean interval from the initial surgery was 47.4 months in group $\mathrm{R}$ and 47.5 months in group $\mathrm{D}(P=.34)$. The early reoperations in 6 patients were due to technical failures of inadequate initial repair, which included dehiscence of a pericardial patch leaflet extension, annuloplasty ring dehiscence, hemolytic anemia (2 patients), and residual leaflet prolapse (2 patients). Progression of disease with recurrent stenosis insufficiency (1 patient with rheumatic disease) and recurrent prolapse from a new chordal rupture (1 patient with degenerative disease) accounted for the late reoperations. All 3 patients with rheumatic disease had their

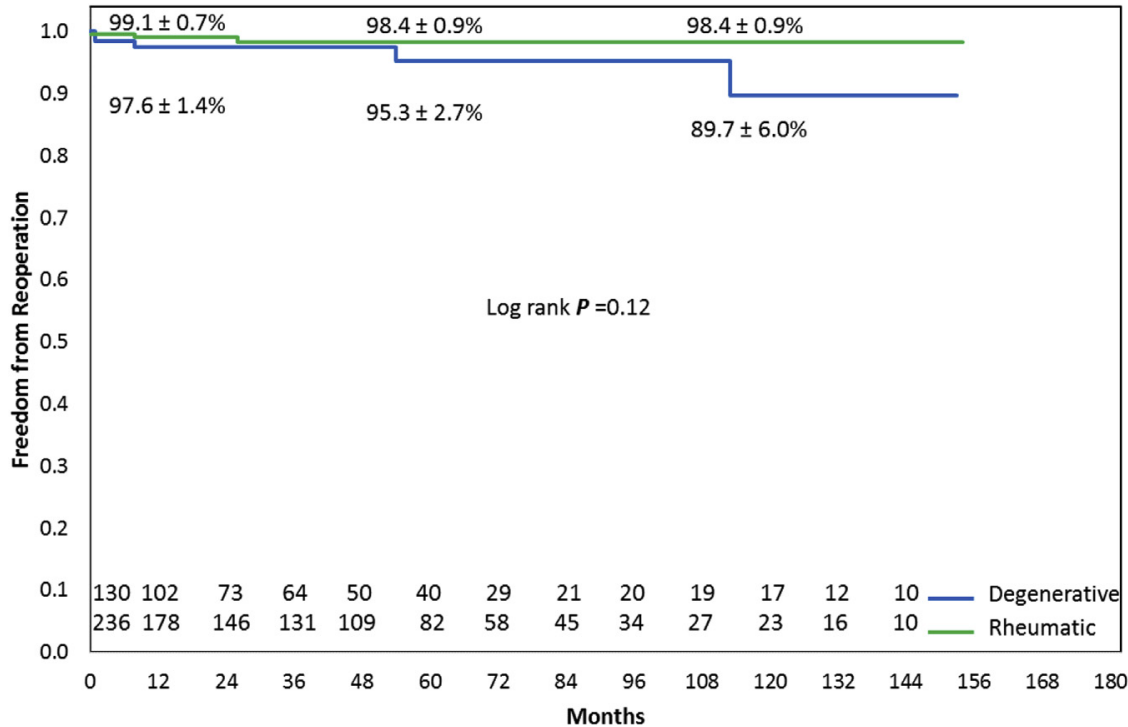

FIGURE 2. Actuarial freedom from reoperation in the group R compared with group D. There was no significant difference between groups $(P=.12)$. 


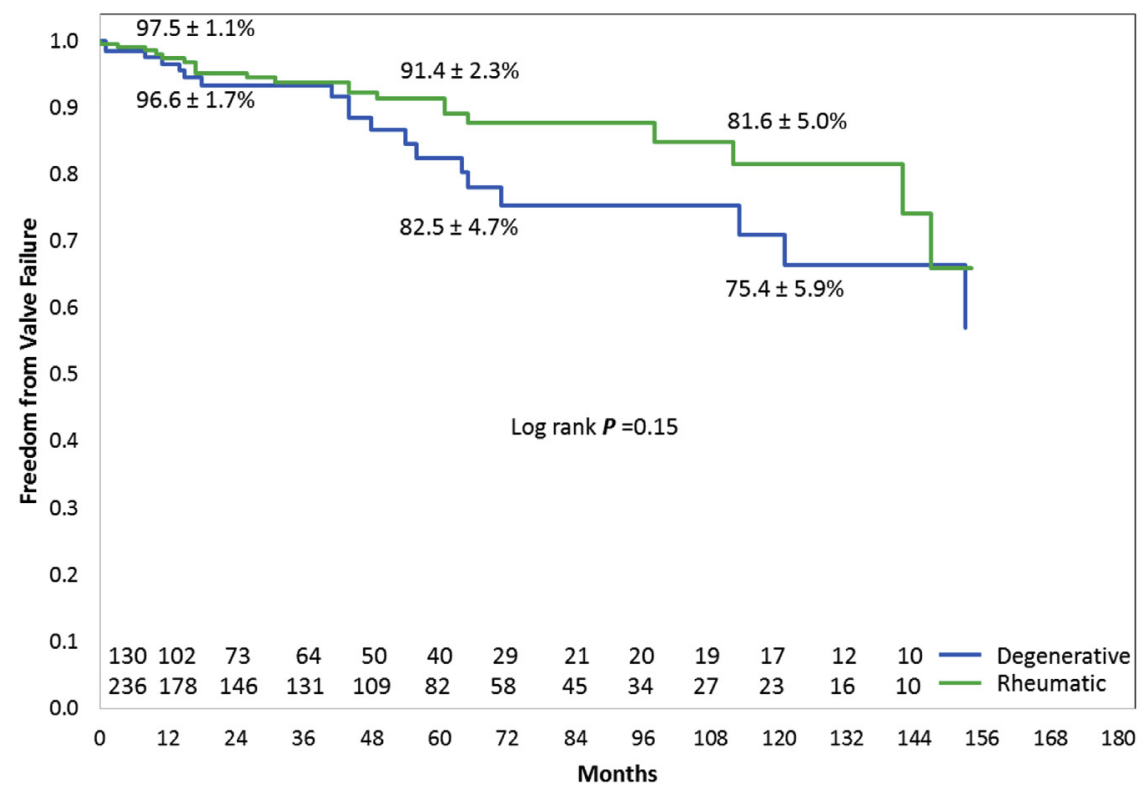

FIGURE 3. Actuarial freedom from valve failure for group R and group $D$. There was no difference between the groups $(P=.15)$. Valve failure was defined as recurrent significant MR of more than $1+$ (mild MR) or MV reoperation.

valves replaced during reoperation, whereas a second MV repair (re-repair) was performed in 3 of the 5 patients with degenerative disease.

Actuarial freedom from valve failure for patients with rheumatic disease at 5 and 10 years was $91.4 \% \pm 2.3 \%$ and $81.6 \% \pm 5.0 \%$, respectively, comparable to degenerative repairs at 5 and 10 years of $82.5 \% \pm 4.7 \%$ and $75.4 \% \pm 5.9 \%$, respectively $(P=.15)$ (Figure 3 ). On univariate analysis of variables in group $\mathrm{R}$, the presence of residual MR greater than 2+ before discharge was the only significant independent predictor of reoperation (hazard ratio [HR], 10.0; 95\% CI, 1.9-52.3; $P=.006$ ), whereas residual MR greater than 2+ (HR, 9.0; 95\% CI, 4.3-18.7; $P<.001$ ) and leaflet procedures (HR, 3.6; 95\% CI, 1.7-7.3; $P=.001$ ) were significant risk factors for valve failure. The other variables of age, sex, cause of valve disease, MS, commissure fusion, commissurotomy, use of annuloplasty ring, and type of annuloplasty ring did not have an impact on reoperation and valve failure.

\section{DISCUSSION}

Rheumatic heart disease is the most common cause of valve disease in the developing nations. ${ }^{19,20}$ The rheumatic process affects the MV in up to $50 \%$ of cases and results in MR, MS, or both. ${ }^{21}$ Replacement of the diseased MV with a prosthesis is associated with suboptimal preservation of ventricular function, anticoagulation-related complications, and reduced survival. MV repair is well recognized as the procedure of choice for patients with degenerative $M R .{ }^{1-3}$ However, valve repair in rheumatic MV disease remains controversial because several studies have demonstrated inferior feasibility and durability. ${ }^{6,7}$ On the other hand, Chauvaud and colleagues ${ }^{10}$ demonstrated good long-term results in repairing diseased rheumatic MVs using Carpentier's reconstruction techniques. More recently, we demonstrated that the durability of MV repair had improved over the years and is comparable to the long-term outcomes repair for degenerative disease. ${ }^{13}$

Nevertheless, repair for rheumatic disease in the extremes of ages poses some unique challenges. In the young, ongoing rheumatic inflammatory activity may predispose to reactivation with failure of the initial repair. ${ }^{8,12,15}$ In our earlier series of rheumatic MV repair, we demonstrated that repair at a younger age ( $<20$ years) was an independent predictor of reoperation and valve failure. ${ }^{13}$ In addition, younger patients had a tendency to be less compliant to medications, including antibiotic prophylaxis. At the other end of the spectrum, chronic rheumatic disease in older adults with "burnt-out" disease is often accompanied with extensive tissue scarring, fibrosis, retraction, calcification, and stenosis, resulting in technical difficulties in repair and potentially compromising durability. ${ }^{21}$ Furthermore, long-term evaluation of outcome in rheumatic MV repair in adults is scarce, and the lack of current available data does not assist in resolving this issue of appropriateness and durability of repair in this cohort.

This present study, which represents a 15-year single-center experience of rheumatic MV repair in adults aged 40 years or more, has yielded some promising results. We have attempted to repair most rheumatic valves that 
were not extensively calcified and had some pliable leaflet tissue. The majority of the survivors in our series had no residual MR $(28.7 \%$ of patients) or $1+$ MR (trivial or mild MR) in another $60.8 \%$ of patients recorded at their last follow-up visit. Most of those who had residual $2+$ MR $(7.2 \%)$ were asymptomatic. Freedom from reoperation for patients with rheumatic disease at 5 and 10 years was $98.4 \%$, comparable to $95.3 \%(P=.12)$ for patients with degenerative disease, attesting to the durability of repair. We also evaluated the end point of valve failure, defined as recurrent significant regurgitation of more than 1+ MR (mild MR) or MV reoperation. Particular importance was placed on freedom from valve failure, which we believe is a more robust and sensitive indicator of long-term durability because performance of the repaired valve is also taken into consideration. In our series, the actuarial freedom from valve failure for patients with rheumatic disease at 5 and 10 years was $91.4 \%$ and $81.6 \%$, respectively, which was again not inferior to the valve failure rates for degenerative repairs of $82.5 \%$ and $75.4 \%$, respectively $(P=.15)$.

It is generally acknowledged that repair for rheumatic MV disease, especially in adults, is technically more difficult, challenging, and complex, ${ }^{12,22-24}$ and often requires modifications of standard techniques to achieve a good result. Chronic rheumatic disease or the "burnt-out" rheumatic disease, which occurs when the active myocarditis and valvulitis have ceased, is often highlighted by the presence stiff and restricted leaflets, commissural fusion, subvalvular thickening, and fusion and calcification, presenting with restricted MR (Carpentier's type III) or MS. ${ }^{21}$ Rankin and colleagues ${ }^{16}$ and El Oumeri and colleagues ${ }^{24}$ have described innovative techniques to perform repairs in these difficult rheumatic MVs. In an earlier publication, we also detailed a stepwise repair technique to mobilize the restrictive rheumatic mitral leaflet and complemented by leaflet extension when there was extensive tissue retraction and leaflet hypoplasia. ${ }^{17}$ Leaflet procedures, which included thinning, shaving, and leaflet extension, were generally performed for severe and advanced forms of rheumatic disease, especially for mixed mitral disease. The leaflet procedures may not be the direct cause of the reduced durability of valve repair, but rather a surrogate marker for advanced mixed mitral disease, explaining the poorer durability associated with these procedures. A similar inference could be made toward the negative impact of commissural fusion on the outcome of rheumatic MV repair as reported by Geldenhuys and colleagues. ${ }^{25}$ However, we did not discover commissural fusion to be a predictor of poor outcome despite the need to perform commissurotomy in 35 patients $(13.8 \%)$ with rheumatic disease. It may be that we adopted an aggressive approach to free the restricted leaflets at the commissures by commissurotomy plus splitting of fused fan chords and papillary muscles on the undersurface of the commissures; in essence, the technique is perhaps better described as valvuloplasty at the level of the commissures instead of merely commissurotomy. Another technical modification was the shift from using chordal shortening and chordal transfer in favor of artificial chordae to treat leaflet prolapse. Chordal replacement was also used in patients with rheumatic disease to replace primary chords that were obliged to be cut to release the leading edge of restrictive leaflet segments.

Improvement in echocardiographic techniques, using TEE with 2-dimensional and more recently 3-dimensional imaging, has greatly aided surgeons in planning a systematic strategy toward successful valve repair. We practice stringent quality control by the mandatory use of intraoperative TEE to assess competency of the repaired MV. We do not accept residual MR of more than grade $1+$ MR because it has been consistently shown to be the predictor for valve failure and reoperation. We are also wary of the consequence of leaving any amount of residual eccentric MR because the eccentric jet can result in hemolysis, often requiring a redo operation. We strive to achieve a leaflet coaptation length of more than $5 \mathrm{~mm}$ to ensure long-term durability of the repair. By adopting an aggressive approach combined with multiple repair techniques plus stringent quality control, we have managed to extend the scope of repair in rheumatic mitral disease in adults aged 40 years or more to respectable average repair feasibility of $65 \%$. In addition to the armamentarium of surgical techniques, the use of antibiotic prophylaxis is crucial, and we advocate oral penicillin as a secondary prevention against rheumatic fever for 10 years or to 40 years of age (whichever is longer) even after a successful valve repair for rheumatic heart disease, as was previously recommended, although more recent guidelines advise lifelong use. ${ }^{26}$ These multipronged approaches have improved our long-term results of MV repair for rheumatic mitral disease in adults in current era, and the outcomes are as durable and noninferior when compared with the results of repair for degenerative disease.

\section{Study Limitations}

This study is a single-center series that is susceptible to referral bias and institution-specific practices. The nonrandomized design may have affected the results because of the presence of unmeasured confounders, procedures bias, or detection bias, despite the use of statistical adjustments. The variations in results depend on the attending surgeon's discretion on different techniques and level of acceptance of the repair results.

\section{CONCLUSIONS}

The durability of MV repair for rheumatic disease in current times has improved and is comparable to the 
outstanding results of repair for degenerative disease, even for adults with "burnt-out" chronic rheumatic disease. Improved repair techniques, adherence to the importance of good leaflet coaptation, strict quality control with the use of intraoperative TEE, and improved medical care have all contributed to the improved long-term results. Therefore, rheumatic cause may not be a predictor of an inferior outcome in the current era of MV repair.

The authors thank the consultants and senior registrars in the Department of Cardiology for the echocardiographic studies, Marini Kamarudin for invaluable secretarial assistance, and Siti Rahmah Shafiee for bibliography resources.

\section{References}

1. Ren JF, Askut S, Lightly GW Jr, Vigilante GJ, Sink JD, Segal BL, et al. Mitral valve repair is superior to valve replacement for early preservation of cardiac function: relation of ventricular geometry to function. Am Heart J. 1996;131: 974-81.

2. Suri RM, Schaff HV, Dearani JA, Sundt TM 3rd, Daly RC, Mullany CJ, et al. Survival advantage and improved durability of mitral repair for leaflet prolapse subsets in the current era. Ann Thorac Surg. 2006;82:819-26.

3. Enriquez-Sarano M, Schaff HV, Orszulak TA, Tajik AJ, Bailey KR, Frye RL. Valve repair improves the outcome of surgery for mitral regurgitation. A multivariate analysis. Circulation. 1995;91:1022-8.

4. David TE, Armstrong S, Sun Z, Daniel L. Late results of mitral valve repair for mitral regurgitation due to degenerative disease. Ann Thorac Surg. 1993;56:7-14.

5. Gillinov AM, Cosgrove DM, Blackstone EH, Diaz R, Arnold JH, Lytle BW, et al. Durability of mitral valve repair for degenerative disease. J Thorac Cardiovasc Surg. 1998;116:734-43.

6. Cosgrove DM, Steward WJ. Mitral valvuloplasty. Curr Probl Cardiol. 1989;14: 359-415.

7. Yau TM, Ei-Ghoneimi YA, Armstrong S, Ivanov J, David TE. Mitral valve repair and replacement in rheumatic disease. J Thorac Cardiovasc Surg. 2000;119:53-60.

8. Duran CM, Gometza B, Saad E. Valve repair in rheumatic mitral disease: an unsolved problem. J Card Surg. 1994;9:282-5.

9. David TE. The appropriateness of mitral valve repair for rheumatic mitral valve disease. J Heart Valve Dis. 1997;6:373-4.

10. Chauvaud S, Fuzellier JF, Berrebi A, Deloche A, Fabiani JN, Carpentier A. Long-term (29 years) results of reconstructive surgery in rheumatic mitral valve insufficiency. Circulation. 2001;104(12 suppl 1):I12-5.

11. Yankah CA, Siniawski H, Detschades C, Stein J, Hetzer R. Rheumatic mitral valve repair: 22-year clinical results. J Heart Valve Dis. 2011;20:257-64.

12. Antunes MJ. Valve repair for rheumatic mitral regurgitation: still worthwhile? J Heart Valve Dis. 2011;20:254-6.

13. Yakub MA, Dillon J, Krishna Moorthy PS, Pau KK, Nordin MN. Is rheumatic etiology a predictor of poor outcome in the current era of mitral valve repair? Contemporary long-term results of mitral valve repair in rheumatic heart disease. Eur J Cardiothorac Surg. 2013;44:673-81.

14. Antunes MJ. Repair of rheumatic mitral valve regurgitation: how far can we go? Eur J Cardiothorac Surg. 2013;44:689-91.

15. Kalangos A. The rheumatic mitral valve and repair techniques in children. Semin Thorac Cardiovasc Surg Pediatr Card Surg Annu. 2012;15:80-7.

16. Rankin JS, Sharma MK, Teague SM, McLaughlin VW, Johnston TS, McRae AT. A new approach to mitral valve repair for rheumatic disease: preliminary study. J Heart Valve Dis. 2008;17:614-9.

17. Dillon J, Yakub MA, Nordin MN, Pau KK, Krisha Moorthy PS. Leaflet extension in rheumatic mitral valve reconstruction. Eur J Cardiothorac Surg. 2013;44:682-9.

18. Enzler MJ, Berbari E, Osmon DR. Antimicrobial prophylaxis in adults. Mayo Clin Proc. 2011;86:686-701.

19. Mclaren MJ, Markowitz M, Gerber MA. Rheumatic heart disease in developing countries: the consequence of inadequate prevention. Ann Intern Med. 1994;120: 243-5.

20. Marcus RH, Sareli P, Pocock WA, Barlow JB. The spectrum of severe rheumatic mitral valve disease in a developing country. Correlations among clinical presentation, surgical pathologic findings and hemodynamic sequelae. Ann Intern Med. 1994;120:177-83.
21. Zakkar M, Amirak E, Chan KM, Punjabi PP. Rheumatic mitral valve disease: current surgical status. Prog Cardiovasc Dis. 2009;51:478-81.

22. Choudhary SK, Talwar S, Dubey B, Chopra A, Saxena A, Kumar AS. Mitral valve repair in a predominantly rheumatic population. Long-term results Tex Heart Inst J. 2001;28:8-15.

23. Mavioglu I, Dogan OV, Ozeren M, Dolgun A, Yucel E. Valve repair for rheumatic mitral disease. J Heart Valve Dis. 2001;10:596-602.

24. El Oumeri B, Boodhwani M, Glineur D, De Kerchove L, Poncelet A, Astarci P, et al. Extending the scope of mitral valve repair in rheumatic disease. Ann Thorac Surg. 2009;87:1735-40.

25. Geldenhuys A, Koshy JJ, Human PA, Mtwale JF, Brink JG, Zilla P. Rheumatic mitral repair versus replacement in a threshold country: the impact of commissural fusion. J Heart Valve Dis. 2012;21:424-32.

26. Gerber MA, Baltimore RS, Eaton CB, Gewitz M, Rowley AH, Shulman ST, et al Prevention of rheumatic fever and diagnosis and treatment of acute Streptococcal pharyngitis: a scientific statement from the American Heart Association Rheumatic Fever, Endocarditis, and Kawasaki Disease Committee of the Council on Cardiovascular Disease in the Young, the Interdisciplinary Council on Functional Genomics and Translational Biology, and the Interdisciplinary Council on Quality of Care and Outcomes Research: endorsed by the American Academy of Pediatrics. Circulation. 2009;119:1541-51.

\section{Discussion}

Dr Gilles Dreyfus (Monte Carlo, Monaco). Dr Dillon, I congratulate you on this presentation. This article reports a comparative study of MV repairs in adults with rheumatic or degenerative disease, and all patients were aged 40 years or more. Your echocardiography assessment showed that more than $30 \%$ in the rheumatic group did not have severe MR, likewise, $20 \%$ in the degenerative group. You also told us that surgery included combined techniques, among which $18 \%$ had a leaflet extension with autologous pericardial patch. Freedom from reoperation at 5 and 10 years was similar. Actuarial freedom from valve failure was superior for rheumatic cases versus degenerative cases. This article raises hope but also many questions. What were your criteria to indicate surgery for patients who did not have severe MR?

Dr Dillon. This group of patients were not only those with isolated MR. They were also patients with concomitant disease. Some of those had mitral pathology as their secondary disease. The indication for surgery in them was for another primary disease, for example, coronary artery bypass grafting or aortic valve disease. Although the mitral pathology was less than severe, they had concomitant repair of the MV as a secondary procedure. I think $10 \%$ of patients undergoing operation had moderate MR.

Dr Dreyfus. You showed that $35 \%$ in the rheumatic group had previous AF before surgery. In a 60 -year-old patient, do you still prefer to do repair in a rheumatic patient with chronic AF, and if so, why, because, of course, the patient will be exposed to taking anticoagulant treatment in relation to the $\mathrm{AF}$ and the risk of failure of the MV repair.

Dr Dillon. Yes, we would prefer to do repair if we can predict that this repair is probably durable, meaning that if this is a relatively simple repair, we would do so compared with inserting a prosthetic valve, because we are thinking that the need for anticoagulation control is less stringent even in the presence of AF. Ideally, we would like to perform MV repair plus the Maze procedure in this patient to completely eliminate the need for anticoagulation.

Dr Dreyfus. How do you predict a repair is going to be easy in a rheumatic patient? 
Dr Dillon. In this group of patients, it's interesting. When we set up to look at these adult patients, we thought our results of rheumatic repairs were going to be terrible compared with the degenerative repairs. However, we hypothesized that this "burntout" group is a little different from the young rheumatic patients. The challenge in the young rheumatic patients is one of recurrent disease or reactivation of rheumatic disease. On the other hand, the challenge in the adult rheumatic patients is one of a technical challenge attempting to repair complex pathology often with advanced disease with leaflet restriction. Certainly, we could do repair in only $65 \%$ of these patients, not all. We excluded those with heavy leaflet calcification and those with stiff, nonpliable, and stuck leaflets. So if we exclude this category, the results can be reproducible in $65 \%$ of patients. One important additional benefit is they do not experience the reactivation of disease, the plight of the young rheumatic population.

Dr Dreyfus. Finally, you told us that surgery has improved, and, for instance, you mentioned the use of autologous pericardium, but it accounts for only $18 \%$ of your patients. By the way, I saw you doing an extension of the posterior leaflet. Do you think that posterior leaflet extension is as effective as anterior leaflet extension to improve coaptation or durability and increase the size of the ring? What is your explanation for the good results you are presenting today?

Dr Dillon. I will start with the leaflet extension procedure. It still remains controversial whether to extend the anterior to posterior. There are numerous publications either way. Our philosophy is to look at the restricted leaflet. In most of our patients (approximately two thirds), the restricted leaflet was the posterior leaflet, with a normal or prolapsing anterior leaflet. To make it more scientific, we measured the anterior leaflet because previous studies on rheumatic repairs showed that a height of $25 \mathrm{~mm}$ or less predicted inferior durability. If we had a height of at least $26 \mathrm{~mm}$ measured on echocardiography or during surgery, or alternatively if we get the anterior leaflet to accommodate at least a 26-mm annuloplasty ring sizer, which is the smallest adult size ring, we generally do not extend the anterior leaflet, and we concentrate on the posterior leaflet. Our results of leaflet extension, although the numbers are not large, did not seem to matter in terms of durability whether the anterior or posterior or both leaflets were extended.

As to inserting a larger ring or not, the size of the ring is determined by the final dimension of the anterior leaflet. Of course, if we extended the anterior leaflet, we used a larger size ring. What we did when we extended the posterior leaflet was to measure the size of the mitral orifice (ie, the size of the annulus instead of the anterior leaflet), and that seemed to allow placement of a larger ring.

In regard to the good results of valve repair, there are multifactorial reasons. First, modification in repair techniques made a difference. We have discussed leaflet extension, and the other is the use of artificial chords. We use artificial chords to treat prolapse compared with earlier in our experience when we used chordal shortening and chordal transfer. In rheumatic disease, the adjacent chords are inherently diseased as well; if we do transfer or shortening, these diseased chords tend to fail. We also use artificial chords to replace shortened restrictive primary chords that were resected. Thus, artificial chords, leaflet extension, leaflet shaving procedure, and extended commissurotomy all helped. Putting in a larger ring after leaflet extension also seemed to confer durability. This is our opinion.

The other issue is the stringent quality control with use of intraoperative echocardiography. Echocardiography has helped us to predict a more durable repair. At the end of the repair, we want to have good leaflet coaptation length of more than $5 \mathrm{~mm}$, and we don't want to have more than 1+ residual MR or any eccentric MR. One of our predictors of poor outcome was residual MR at discharge. We also use 3-dimensional echocardiography, which is especially helpful when we have a second pump run to isolate the segment where there is residual regurgitation. The advice from guidelines and compliance of lifelong rheumatic antibiotic prophylaxis with penicillin also helps in durability. Also, if we can overcome the mindset and technical challenge of repair in rheumatic patients, repair in rheumatic adults is potentially more durable than in the young because the adults are free of reactivation of disease, that is, the disease is burnt-out. Finally, perhaps, some persistence, perseverance, and experience of the operators toward the repair procedures were beneficial.

Dr Dreyfus. Thank you and congratulations for your presentation.

Dr Robert Guyton (Atlanta, $G a$ ). You have talked to us about the limitations that you place on regurgitation at the end of the operation. With these thickened leaflets with the abundant use of size 26 rings, I begin to worry more about stenosis than regurgitation. What mean gradient would you find acceptable at the end of the operation by echocardiography, and when you look at valve failure postoperatively, have you also included stenosis, and what level of stenosis do you consider valve failure in the postoperative follow-up?

Dr Dillon. Valve failure was defined as recurrent MR or reoperation, which included stenosis as well if the stenosis was severe enough to require reoperation. Thus, we did consider MS in our assessment. Our most common ring sizes were 28 and $30 \mathrm{~mm}$ for both the groups with and without leaflet extension. We try not to use a 26-mm ring.

Dr Guyton. What gradient do you consider acceptable at the end of the operation?

Dr Dillon. What we consider acceptable is a mean gradient of less than $5 \mathrm{~mm} \mathrm{Hg}$.

Dr Vinay Badhwar (Pittsburgh, $P a$ ). All of us who are currently repairing rheumatic patients have much to learn from your laudable experience. I wanted to hinge my question on a specific point to follow up on Dr Dreyfus' comment on predictors.

Your comments were surrounding predictors of post-repair success by echocardiography. What about pre-repair predictors on the evaluation of your echocardiography to determine feasibility of MV repair or surgical planning? In degenerative myxomatous disease, we have become experienced with preoperatively planning the repair on the basis of echocardiographic anatomy. Do you have specific elements that you look for in planning the feasibility of rheumatic repair, such as subvalvular thickening, subvalvular apparatus density, or other anatomic predictors that may predict feasibility and technique used, that is, the use of augmentation or not?

Dr Dillon. Yes, we do have some echocardiographic guidance. We measure both leaflets, the length of the leaflets as a guide to the necessity of leaflet extension. We also look for commissural 
thickening, fusion, and the amount of calcification. Those have helped us in planning our repair. In cases of dense calcification involving both leaflets, we probably would not attempt a repair, although it is feasible to go for if the rewards of repairing the valve in that particular patient were high. We tried to look at leaflet thickening, and, to us, it is difficult to predict that when we compare it with intraoperative findings.

To have a preoperative predictor of success of feasibility of repair, right now we would attempt to repair every regurgitant rheumatic disease short of those that are heavily calcified or totally rigid. Any leaflet that has some amount of pliability, not with a heavy amount of calcification, we would try to repair.

Dr Steven Bolling (Ann Arbor, Mich). That was a great series. I have a technical question. How far out do you take that commissurotomy? Do you take it past the disease point? Do you actually take it into the annulus on both sides?

Dr Dillon. I take it just short of approximately 2 to $3 \mathrm{~mm}$ from the annulus. Earlier in my experience, I took it right up to the annulus. I ended up having to put a stitch there, because it frequently leaked there. So what I do is start just short of the annulus and look at the underside of it, look at the fusion of the chords, fusion of papillary muscle, and release the fused leaflet and subvalvular apparatus. Perhaps you could share your experience.

Dr Bolling. So pretty far beyond the natural commissure, almost all the way?

Dr Dillon. Exactly, almost all the way but not quite reaching the annulus.

\title{
EDITORIAL COMMENTARY
}

\section{Mitral valve repair in patients with rheumatic heart disease: What are the limits?}

\author{
Hartzell V. Schaff, MD
}

See related article on pages 771-9.

Mitral valve repair is preferred over prosthetic replacement because, for most patients, successful operation not only relieves the hemodynamic burden of valve regurgitation and resulting symptoms, but also frees them from the hazards of chronic anticoagulation. Moreover, numerous studies have demonstrated that repair of severe mitral valve regurgitation improves late survival, even for those patients who have few or no symptoms. ${ }^{1,2}$ However, most outcome studies of valve repair have focused on patients with degenerative mitral valve disease, and patients with rheumatic heart disease present special challenges.

The study by Dillon and colleagues ${ }^{3}$ from the National Heart Institute in Malaysia is important for several reasons. First, the authors have focused on adult patients, for whom the option of valve replacement might be more

From the Division of Cardiovascular Surgery, Mayo Clinic, Rochester, Minn. Disclosures: Author has nothing to disclose with regard to commercial support.

Received for publication Dec 2, 2014; accepted for publication Dec 3, 2014; available ahead of print Feb 11, 2015.

Address for reprints: Hartzell V. Schaff, MD, Division of Cardiovascular Surgery,

Mayo Clinic, 200 First St SW, Rochester, MN 55905 (E-mail: schaff@ mayo.edu). J Thorac Cardiovasc Surg 2015;149:779-80

$0022-5223 / \$ 36.00$

Copyright (c) 2015 by The American Association for Thoracic Surgery http://dx.doi.org/10.1016/j.jtcvs.2014.12.009 acceptable than it is for children and young adults, where anticoagulation is especially problematic. Second, they compared their large series of patients with rheumatic valvular disease undergoing mitral valve repair with patients having repair of mitral valve regurgitation that is caused by degenerative valve disease. The good results that they demonstrate, $1 \%$ early mortality for patients undergoing isolated mitral valve repair, and $98 \%$ freedom from reoperation at 5 and 10 years postoperatively, reflect the skill and experience of their clinical team. In almost every respect, outcomes of patients with rheumatic heart disease having valve repair were similar to outcomes of patients having valvuloplasty for degenerative mitral valve disease.

A few caveats apply. First, even though their study population included only patients aged $>40$ years ("burntout" rheumatics), the average age of these patients was 54 years, and the average age of their patients with degenerative valve disease was only 55 years. These ages are a decade younger than those of the patients we see who are referred for repair of mitral valve regurgitation. ${ }^{1}$ Whether the same results demonstrated by these authors can be achieved in patients who present later in life is unclear.

Second, Dillon and his surgical colleagues have selected patients carefully, as they should. Among all patients aged $>40$ years undergoing mitral valve procedures with rheumatic heart disease, mitral valve repair was undertaken in slightly $>40 \%$ of patients, and this rate of repair was 